\title{
Research on Agricultural Value Chain Financing Model
} Hao Dong ${ }^{1, a^{*}}$, Wang Zengmei ${ }^{2}$ and Li Na ${ }^{3}$

${ }^{1,2}$ Shandong Vocational College of Science and Technology, Weifang, Shandong, China, 261053

${ }^{3}$ People's Government of Guanzhuang Town, Anqiu city, Shandong Province

a 475536334@qq.com

${ }^{*}$ Corresponding author

Keywords: Agricultural Value Chain, Financing Model, Agricultural and Rural Areas.

\begin{abstract}
Agricultural value chain financing mode is still in the development stage in China. According to different sources of funds, agricultural value chain financing can be divided into internal financing and external financing. Practice has proved that the financing mode of agricultural value chain plays a positive role in reducing credit cost, reducing business risk and improving agricultural financing environment. However, the current domestic agricultural value chain financing also has problems such as unbalanced financing in all links, relatively single financing mode, unstable risk control and inadequate financial supervision. Therefore, the government, Banks, leading enterprises, farmers and other levels to improve.
\end{abstract}

\section{Introduction}

The report of the 19th National Congress of the Communist Party of China stated that to implement the strategy of rural revitalization, we must adhere to the priority development of agriculture and rural areas. In 2018, the Central Document No. 1 proposed to strengthen the innovation of financial services and improve the ability and level of financial services for rural revitalization. As a developing country, China needs to fully learn from the successful experiences of other countries in implementing rural revitalization. Since the concept of agricultural value chain financing was put forward in 2003, the successful experience of many countries shows that encouraging multiple types of agricultural business entities to integrate into the industrial chain and value chain can effectively improve the comprehensive benefits of agriculture.

\section{The concept of agricultural value chain}

In 1985, American scholar Michael Porter first proposed the concept of "value chain". Kaplinsky has expanded on the basis of the "value chain" and proposed the "industry value chain". "Value chain" sometimes refers to the value chain of an enterprise, and sometimes refers to the value chain of an industry.

Agricultural value chain financing refers to the financial financing behavior based on market trading relationships between various participants within the agricultural value chain, or between financial institutions such as banks and banks outside the agricultural value chain. Agricultural value chain financing treats agricultural value chain participants as a whole, and solves agricultural financing problems through financing activities between internal participants in the value chain and between financial institutions such as participants and external banks in the value chain. To a certain extent, it has expanded the ways and means of agricultural financing, and alleviated the difficulty of financing agriculture. 


\section{Analysis of financing model of agricultural value chain}

\subsection{Agricultural value chain financing}

Financing within the agricultural value chain is generally characterized by direct financial support from leading enterprises or small and medium-sized enterprises in the value chain, including direct cash financing and financing in kind, including advance payment, direct borrowing or credit sales of production materials. form.

\subsubsection{Intra-chain financing mode of "leading enterprises + farmers"}

The "leading enterprise + farmer" financing model was born in the 1980s and is the starting point for the development of agricultural industrialization. The "leading enterprise + farmer" financing model is the starting point of agricultural industrialization, mainly because the leading enterprises sign the order contract with the farmers and extend the funds to the farmers through the value chain. On the one hand, farmers use agricultural products as collateral, leading enterprises provide loans to farmers through loans; on the other hand, leading enterprises directly provide farmers with seeds, fertilizers and other raw materials for production, and farmers provide high-quality agricultural products according to contracts. Generally speaking, leading enterprises will implement protection measures for farmers and implement protection prices at the time of acquisition. The leading enterprises will carry out further value-added activities such as processing of the purchased agricultural products, and finally bring the finished products to the market for sales. The leading enterprises sign the contract with the farmers to drive the farmers to carry out specialized production, thus achieving the integrated operation of production, processing and sales.

\subsubsection{Intra-chain financing mode of "leading enterprise + professional cooperative + farmer"}

With the change of production mode, the single farmer's production mode has gradually changed into the intensive production of professional cooperatives. More and more leading enterprises no longer sign production agreements with scattered single farmers, but the company contracts with professional cooperatives that farmers spontaneously organize. The professional cooperatives will uniformly acquire the products from the farmers, and then the professional cooperatives will provide them to the leading enterprises. Leading enterprises have reduced the cost of orders by signing contracts with professional cooperatives. On the other hand, compared with the direct contract with farmers, the contractual default rate can be greatly reduced, and the interests of leading enterprises can be guaranteed and benefit the value chain. The flow of funds within the chain. Compared with the "leading enterprise + farmer" financing model, it is more conducive to the stability of the entire value chain.

\subsection{Agricultural value chain out-of-band financing}

\subsubsection{Out-of-chain financing mode of "bank + leading enterprises + farmers"}

Under the out-of-network financing mode of "bank + leading enterprises + farmers", there are two ways for banks or other financial institutions to inject funds into the agricultural value chain: one is based on the long-term cooperative relationship between leading enterprises and farmers, and is led by leading enterprises. Provide guarantees for farmers, apply for loans from banks or other financial institutions, bank loans are directly distributed to farmers in the value chain; and banks or other financial institutions directly increase funds by leading enterprises to directly inject funds into leading enterprises. After the enterprises receive financial support, they provide the funds needed for production in the value chain by providing means of production and technology, and direct borrowing. In the entire agricultural value chain with leading enterprises as the core, leading enterprises have close interests with other participants in the value chain. Banks and other financial institutions take the leading enterprises as the core and inject funds into the entire agricultural value chain.

3.2.2 Out-of-chain financing mode of "bank + leading enterprise + professional cooperative + household"

Under the out-of-network financing mode of "bank + leading enterprise + professional cooperative 
+ farmer", banks or other financial institutions provide financial support for farmers based on the cooperative relationship between leading enterprises, professional cooperatives and farmers, with professional cooperatives as an intermediary. First, the professional cooperatives apply for loans to banks or other financial institutions by means of an order contract with the leading enterprises. The banks provide financing for professional cooperatives, and then the professional cooperatives lend the funds to the farmers. After the professional cooperatives purchase the agricultural products produced by the farmers, they are uniformly sold to the leading enterprises. When the funds are settled, the bank signs an agreement with the leading enterprises. The leading enterprises assist the bank to withhold the loan principal and interest of the professional cooperatives in the purchase of agricultural products, and pay the balance after deducting the principal and interest of the loan to the professional cooperative.

\section{Problems in financing agricultural value chain}

\subsection{Unbalanced financing in all aspects of the agricultural value chain}

At present, China's existing agricultural value chain financing model is still not perfect. For the production chain at the front end of the value chain and the sales chain at the back end of the value chain, there are more financing, while the processing enterprises at the intermediate link are relatively weak. The main reason is that processing enterprises are mostly small and medium-sized enterprises, which have the characteristics of small scale, low credit and lack of collateral. There are huge obstacles in financing. However, the value chain is a whole. If there is a problem in any one of the links, it will affect the overall efficiency. The SMEs in the middle link are the most important one. It plays a role in linking the past and the lower, and has the benefit to the entire value chain. important influence. In addition, the imbalance of financing in all aspects of the agricultural value chain will lead to serious consequences. On the one hand, there will be no return of funds, which will increase the non-performing loans of financial institutions; on the other hand, it will lead to the lack of stability of the agricultural value chain, even the chain. Interrupted, thus deepening the financing difficulties in the process of rural industrial integration development.

\subsection{The financing model of each link in the value chain is relatively simple.}

At present, China's agricultural value chain financing model mainly focuses on "company + farmer" and agricultural value chain financing model based on contract farming. First, due to the lack of stability in the agricultural value chain, circulation is blocked; second, financial institutions have insufficient product innovation and financial support. The singularity of the financing model limits the development of the participating entities in the value chain and the extension of the agricultural value chain, thus affecting the realization of the overall benefits of the agricultural value chain.

\subsection{Risk control issues stand out}

China's agricultural value chain financing model is still in the development stage, and the risk problem is outstanding. On the one hand, the quality of farmers is low, there are many uncertainties in establishing cooperative relations with enterprises, and the risks are high. On the other hand, SMEs in the middle of the value chain lack a sound financial management system and internal control system, and the technical level is low. The risk is more difficult to control. The existence of these risks leads to an increase in the instability of the value chain, which exposes financial institutions such as banks to great risks.

\subsection{The financial management system is not sound}

On the one hand, the government's attention to small and micro enterprises is not high, and there is no guiding policy for its financing, which makes banks less financial support for small and micro agricultural enterprises; on the other hand, local governments have limited platforms for agricultural enterprises to expand. This has led to less funding for banks; in addition, the distribution of formal 
financial institutions in rural areas is uneven, the number of rural financial institutions is small, and large banks are reluctant to lend to rural areas. The diversified demand for financial services in the integration and development of rural industries cannot be effectively met, resulting in the financing of rural industrial integration development being blocked.

\section{Countermeasures and suggestions}

As an effective means to solve the problem of agricultural financing, agricultural value chain financing, through the comparative analysis of different financing models, found that various financing models have their own advantages and disadvantages. Therefore, optimizing the agricultural value chain is essential.

At the government level, we must first increase the support for agricultural value chain financing in agricultural industrialization operations and increase the degree of agricultural industrialization. Second, we must build a platform for investment and guide social capital into the agricultural value chain. Finally, improve the risk management system, accelerate the development of policy-based agricultural insurance, and reduce the financing costs of farmers.

At the bank level, we must first increase credit support for SMEs. Second, we must adapt the banking financial services to the characteristics of agricultural production. Finally, credit risk control can be strengthened, insurance and guarantee systems can be established, and bank credit risks can be dispersed.

At the company level, leading enterprises must continuously enhance their own strength and maximize their leading role. Secondly, the leading enterprises should combine the interests of the farmers with their own interests, and allow the farmers to participate in the distribution of the company's interests in the form of shareholdings or the company to link the interests of the farmers with the company's operations in the form of rebates, and improve the enthusiasm of the farmers. Finally, strengthen cooperation with professional cooperatives and improve the level of agricultural management.

At the farmer level, it is necessary to focus on improving credit levels and avoiding credit risks. Second, we must actively learn advanced farming techniques, increase agricultural productivity, and reduce production and operation risks. Finally, strengthen the contact and cooperation with leading enterprises and professional cooperatives, and rely on the agricultural value chain to obtain financial support.

\section{Acknowledgment}

This research was financially supported by Shandong Provincial Federation of Social Sciences (Grant NO. 18-ZC-JJ-04 ) and the Shandong Provincial Social Science Planning and Management Office ( Grant NO.770 ). At the same time, This research was a phased achievement of the key research project of Weifang Social Science Planning (Grant NO. 85 ) in 2019 and the key project of Enterprise Training and Employee Education in Shandong Province ( Grant NO. 2019-025 ) in 2019.

\section{References}

[1] Yang Zhaoting, Meng Weifu, Resolving the financing difficulties of farmers' professional cooperatives based on agricultural value chain: mechanism, problems and countermeasures, Southern Finance, 2017 (03): 91-98.

[2] Wang Xueyou, Research on innovative models of agricultural value chain financing, Anhui University of Finance and Economics, 2016. 
[3] CHENG Lei, ZHANG Qing-liang, Information Asymmetry and Its Solution in Agricultural Value Chain Financing in China, Journal of Tongling College,2016,15(03):11-15.

[4] Li Jianying, Zhang Wentian, Tian Wei, Research on Foreign Agricultural Value Chain Financing Models, Modern Economics Research, 2015(12): 81-85.

[5] Zhang Zhen, Wang Juan, Analysis of the current status of agricultural value chain financing in China, Foreign Trade and Economics, 2015(10): 106-107+136. 